\title{
Normative Consent Is Not Consent
}

\author{
NEIL C. MANSON
}

The UK has an opt-in system of consent for postmortem organ donation. More specifically, the Human Tissue Act 2004 prohibits the removal, storage, and use of organs postmortem for a range of "scheduled purposes"—which include transplantation-unless "appropriate consent" has been given. ${ }^{1}$ Appropriate consent can be given by the donor premortem by signing and carrying a donor card, or by opting in to a donor registry. In the UK only 25 percent of the population is registered, although a much higher percentage of these people claim to be willing to donate. ${ }^{2}$ Although such evidence must be taken with caution-it is all too easy to say that we are in favor of doing something when we don't have to commit to doing it-it would seem that many individuals' preferences and wishes are not acknowledged. That is, many individuals seem to be willing to consent but, in fact, do not get around to making an explicit act that signals, and provides evidence of, their consenting. This is, perhaps, not surprising. There are familiar kinds of psychological inertia that may stand in the way of turning our wishes or desires into an explicit, public commitment. ${ }^{3}$ This deficit in explicit consent might not be a problem if there were a surplus of organs. But each year, many people suffer greatly, and many die, while waiting for transplants. ${ }^{4}$ An increase in organ donation would thus serve to benefit many, in substantive and important ways. Although the deceased donor has no use for her organs, a recipient is given additional years of life or an improved quality of life. With this striking contrast in costs and benefits in view, one tempting solution is an opt-out system. Rather than requiring an explicit act that signals, and provides evidence of, consent, opt-out systems presume the consent of individuals unless the agent chooses to opt out. That is, the onus is put on the individual to explicitly signal (and provide evidence of) a refusal to allow his or her organs to be used. ${ }^{5}$ Opt-out systems require institutions and systems to be in place to ensure that individuals know that it is within their power to opt out, and to offer them the opportunity to opt out in an easy, costless way. Given people's apparent inertia with regard to explicitly signaling preferences that they claim to have, opt-out systems seem to allow increased procurement of organs in an unproblematic way.

But opt-out systems are taken to be problematic for a number of reasons. First, presumed consent is not an explicit act of consent-indeed, for some, it is not consent at all. ${ }^{6}$ Explicit acts of consent are actions by which an agent knowingly expresses her willingness to set aside certain rights that she has. But inaction, it may seem, cannot perform this role in the same way, or with the same degree of assurance. An agent's inaction may reflect her ignorance or her decisional inertia, rather than being an expression of a decision to refrain from opting out.

We have already noted that an appeal to people's expressed attitudes about organ donation may not correlate with the decisions they would actually make. Respondents recognize that organ donation is an estimable thing to do. It is all 
too easy to say that one is in favor of $x$ or that one will do $y$ when there is nothing about the communicative context that binds one to doing so. Saying is one thing; doing is another. So the aforementioned line of argument in favor of an opt-out system (that it is simply taking up the slack left by our decisional inertia) is questionable.

Another broad concern about opt-out systems is that such systems are politically sensitive. In a world in which public opinion matters to policymakers and in which media actors have their own interests and agendas, the change from an opt-in to an opt-out system would raise difficulties. For example, consider the following remark in an opinion piece on the website of the UK's right-of-center Spectator magazine, made during the UK Organ Donation Taskforce's deliberations:

I object to the principle that I have to take a step, or sign a form, or tick a box to prevent the State from taking ownership of my corpse. . . What the Prime Minister now proposes is effectively the nationalisation of the body - with a new "right" to opt out of the otherwise automatic procedure that your corpse will be stripped of organs for recycling. I am squeamish at the suggestion that my dead body is grabbed by the State, a bit like a biological inheritance tax, unless I take the step of withdrawing my "presumed consent."

It is all too easy to represent opting out as part of an ever-expanding reach of state power, or as indicating the diminishment of individual liberty.

So, there are problems with an explicit consent (opt-in) model and a presumed consent (opt-out) model. A recent proposal about organ donation seeks to avoid the problems associated with both of these models while, at the same time, increasing the supply of organs for transplant.

The basic argument runs thus: if it is wrong of people to refuse consent to donation, then we may be permitted to take their organs, although they have not actually consented (explicitly or implicitly). We need not presume anything about whether someone would actually have consented, given the opportunity rather, we are entitled to treat them as if they had, simply because it would be wrong of them not to do so. ${ }^{8}$

This is a normative consent model for organ donation. The aim here is to clarify and explain this model; in doing so we will see that, first, it is misleading to frame it as a "consent" model at all-normative consent is not consent. Second, if the theory is defensible, although it may have something in common with opt-out models, it implies an extremely radical departure from standard opt-out models given that it in fact rejects the assumption that the use of organs postmortem is prohibited without consent. It should be stressed here that our focus is an abstract, philosophical one, and, as such, we must leave it to others to assess how the normative consent proposal might be implemented-or might be impossible to implement-in this or that specific jurisdiction.

\section{What Is Normative Consent?}

The idea of normative consent is drawn from the political philosopher David Estlund, who uses it in a different context. ${ }^{9}$ Estlund's concern is with consent 
theories of political authority, in which the presumed or hypothetical consent of citizens is the source of political authority. Such theories are notoriously problematic: how can anything other than actual acts of consent by citizens justify the authority of the state? This question has much in common with the challenge faced by opt-out systems: how can anything other than actual acts of consent justify the use of organs postmortem? A little more detail of Estlund's theory will help. Consent theories of political authority involve two assumptions:

1) Consent is necessary for political authority.

2) Consent is sufficient for political authority unless consent is invalid or nullified (nullity conditions).

Nullity conditions include coercion, ignorance, and deception. An act of consent only has normative force if it is uncoerced and adequately informed. Estlund then argues that there are normative nullity conditions for both consent and refusals. The idea of normative nullity condition is that an act of consent (or refusal) is invalid or nullified if the agent ought not to consent (or refuse) in that context. These claims are then used to derive the claim that in some contexts an invalid refusal can have the same normative force as a valid act of consent. This may seem very odd, but Estlund offers the following kind of example. Suppose that there is a plane crash in which an experienced flight attendant is trying to save lives. She tells the uninjured passengers, "Look, we can save these people, but you need to do what I say." Estlund suggests not only that it would be wrong of a passenger not to consent to the authority of the flight attendant, but that, if he did not, then his refusal is nullified for normative reasons. The passenger is not exempt from the obligation to assist simply because he does not accept the obligation. The passenger is thus under the same obligation that he would have been under had he consented.

In this case there is a normative nullity condition, such that the invalidated refusal has the same normative force as valid consent. Estlund applies this idea more generally to the justification of political authority: in some cases political authority does not need to be based on the actual consent of citizens but should be based on their normative consent-on the consent that they ought to give, whether or not they give it. It is this line of thought that Saunders applies to organ donation. Given that postmortem organ donation is of minimal cost to the donor and can be of vast benefit to recipients, there is a strong, prima facie duty to donate. Because of this obligation, a person's absence of consent can be nullified. Given that people ought to consent, "we are entitled to treat them as if they had [consented], simply because it would be wrong of them not to do so." ${ }^{10}$ The normative consent model is not to be confused with a version of presumed consent. It is not that we can presume that people would consent because (1) they will, in general, decide to do what is right or because (2) there is evidence that many would explicitly consent but fail to do so for reasons of inertia. Rather, the argument is a normative one: the strength of the duty to donate nullifies the absence of an act of consent.

\section{Some Initial Objections to Normative Consent}

Some have objected that a normative consent system underestimates the costs, risks, and harms associated with organ donation (e.g., distress caused to relatives by the removal of organs without explicit prior consent). ${ }^{11}$ However, such an 
objection could, in principle, be met in a way that preserves the normative consent model. First, we might factor in an additional power of family veto, although this power would be more explicit and coherently formulated than the current UK de facto practice. Second, the normative consent theorist could run a more subtle consequentialist argument that factors in these costs: although the harms and costs are not negligible, they are vastly outweighed by lives saved.

A second line of objection is that normative consent is nothing more than organ conscription. ${ }^{12}$ But this objection misunderstands the nature of the model. The model is designed as an improvement on presumed consent justifications that underpin an opt-out model. It is not meant to be the basis for a conscription model. As we shall see subsequently, people still have the option of opting out, perhaps for justifiable reasons (e.g., religious beliefs) or even for unjustifiable reasons (they don't want to, they have crazy beliefs that the prime minister wants to "nationalize" their body, etc.). Some people may wrongly opt out, but the normative consent model seeks to retain a vestige of the importance of individual autonomy. The model targets the silent, inert masses who make no act of consent or refusal. As Saunders puts it, for those who do not opt out, "we are allowed to use their organs, not because they have actually consented or because we presume consent on their part, but simply because they morally ought to consent and that makes their lack of actual consent normatively irrelevant." 13

A third, related objection is that the model paves the way for a "totalitarian" system. ${ }^{14}$ But, as with the previous objection, this seems to misunderstand the nature of the proposed system. Totalitarian systems tend not to give much weight to opting out (imagine a dictator who says, "All must cut down their trees to provide wood for the state . . unless you don't want to, in which case, please opt out"). ${ }^{15}$

\section{Are There Normative Nullity Conditions on Consent?}

Although these initial objections do not undermine the normative consent model, there is something problematic about it. In particular, normative consent theory rests on the idea that there are normative nullity conditions on consent. What could a normative nullity condition be? Consider the French dwarf tossing case in the early 1990s: the parties all consented, but the consent was deemed to fail to render the practice permissible (for dignitarian reasons). ${ }^{16}$ So, this might seem to be a nice example of a normative nullity condition. The fact that the participants ought not to engage in the activity renders their consent invalid. But is this really a normative nullity condition? Rather than holding that there are nullity conditions that have nothing directly to do with the misdirection or overwhelming of the right-holder's will, we can view such cases in a different, and more plausible, way.

The following list illustrates how things seemed to the participants in the dwarf throwing (both thrower and "throwee"):

- Normative start position: $\mathrm{S}$ is under a conditional obligation to refrain from tossing $\mathrm{R}$ in the air, unless $\mathrm{S}$ consents.

- Normative act: R validly consents to S's proposal [to toss him in the air].

- Normative end position: $\mathrm{S}$ is not prohibited from tossing $\mathrm{R}$ in the air.

But the French court's judgment is that the participants were simply wrong to frame the normative context in this way. In particular, they reject the participants' 
construal of the normative starting position. The courts decided, on dignitarian grounds, that some claim rights (like the right of a dwarf not to be tossed in the air) are inviolable, and they cannot be waived. In such a context it is true that consent cannot play a normative role, but this is not because the consent is nullified but because, given the normative context, consent is not applicable.

Nullification (or invalidity) is not the same as a lack of applicability. For example, suppose I falsely assume that I have the power to waive some of your rights. I "permit" someone else to take your car, or have sex with you. It would be bizarre to claim that this error about the normative situation is a case in which my consent is rendered invalid because I ought not to do so: it simply has no role to play.

The same kind of problem arises with Estlund's own example noted previously. The unhelpful survivor views himself as being under no obligation to obey the flight attendant. Estlund claims that the survivor is under an obligation. If Estlund is right, then this means that the normative starting position is one in which the survivor is simply wrong about the obligations he is under. So, what the example shows is not that there are additional normative nullity conditions for consent, but only that there can be errors about what types of obligations an agent is under, or what rights the agent has: someone may wrongly assume that he or she is in a context in which rights are waivable or that an obligation is conditional on consent. Someone may mistakenly think that he or she is in a context in which consent can play a normative role, when it cannot.

At this point the normative consent theorist might reply that this is a mere terminological quibble about what we mean by "nullity conditions." In response, we might point out that what matters here is that we are clear about the very important differences between the familiar will-involving nullity conditions and the normative nullity conditions. Standard nullity and validity conditions are conditions that an act fails to meet (because the agent's will has been forced or misdirected). But it is an act made in a context in which consent-considered as a type of action-can and would have normative force. That is, the particular (seeming) act of consent is nullified in a context in which the type of normatively transformative action (giving consent) is appropriate. In contrast, the normative consent theorist's nullity condition comes into play in contexts in which the type of action-giving consent-has no role to play. Given these very substantive differences, it is misleading to use the same term as that used for will-involving nullity conditions like coercion and deception.

\section{The Symmetry Problem}

So far we have seen that normative consent theory seems to involve a fallacious move right at the start, conflating nullity conditions with substantive normative claims about what we are obliged or permitted to do. Suppose we set aside this worry for now. Estlund wants to apply this notion of a nullity condition to acts of refusal rather than acts of consent. The unhelpful person's refusal to assist is nullified because they ought not to refuse. But, Estlund notes, there is a peculiar asymmetry here. Standardly a null—or invalid—refusal will leave things as they are. This is because the normative change requires a positive act. For example, suppose someone is coerced into refusing to sign a contract. The nullifying effect of this is not to make it as if the person had validly signed the contract; it is, rather, to leave the person without having undertaken the obligation. 
So why does Estlund think that a nullified refusal should have the same effect as a valid consent? There is a simple enough explanation (although this is not one that Estlund would endorse). The explanation is that normative consent theory conflates substantive normative claims with nullity conditions. Given this conflation, it is perhaps not surprising that in these special "normative" nullity cases Estlund thinks that a (normatively) null refusal has the same effects as valid consent.

We have already made use of a simple template that captures normative change: one that takes us from a normative start position, via a normative act, to a normative end position. Suppose we focus on a normative end position:

- Normative end position: $\mathrm{A}$ is under an obligation to B to do F.

What Estlund's normative consent theory seems to come down to is the fact that we might be able to reach this end position in two different ways.

1) A two-step route via a normative act:

- Normative start position: A is under no obligation to B to do F.

- Normative act: A consents to be under an obligation to B to do F.

2) A direct substantive route without any normative act:

- Normative start position: A is under an obligation to B to do F.

If we believe that the direct substantive route is the only correct one, then we simply deny that consent has a role in reaching the end position-although people might mistakenly think that the consent route was correct. Let us return to the flight attendant example. The unhelpful passenger construes the normative situation as one in which a consent route is appropriate-type (1)-and he believes that if he refuses (or fails to consent), he will not reach the normative end position of being under an obligation to the flight attendant. Estlund, in contrast, argues that the correct assessment of the normative situation is type (2): the passenger is under an obligation to obey whether or not he refuses. But all that this shows us is that there can be two different routes by which A can be placed under an obligation to B (one involving consent and the other not) and that agents can be in disagreement about which is the correct construal of the normative situation. If the direct substantive route is correct, then acts of consent or refusal are epiphenomenal or redundant. But this is, once again, just to insist that consent has no role (and not, as it might seem, that it is applicable but nullified).

\section{Normative Consent and Organ Donation}

Our analysis so far makes it clear why normative consent theory might seem to be applicable to organ donation in a useful way: in both cases theorists face the challenge of how a lack of explicit consent might have normative force. One point to note is that Estlund's theory is focused on consent as agreement. But consent in organ donation is permissive. ${ }^{17}$ In Estlund's examples, at the normative starting point, a citizen is under no obligation to certain parties (those who constitute the government) but at the normative end position she is under such an obligation: normative consent is meant to provide the bridge between these two positions. 
For permissive consent, by way of contrast, the normative starting point is as follows:

- Normative start position: It is impermissible for S to do F unless R consents.

In the case of organ donation, the start position involves a prohibition against the removal, storage, and use of organs for transplant unless appropriate consent is given. The consent here is permissive: in giving consent, the potential donor-let us leave aside family consent-renders a type of action permissible that would otherwise be prohibited. Now, all agree that there are good, but defeasible, reasons to gain organs for transplant (for $S$ to do $F$ ): such actions serve to benefit others in substantive and important ways. But the prohibition against $S$ 's doing $F$ stands as an obstacle to doing $\mathrm{F}$. The obstacle is removed if R explicitly consents. But what of those who do not consent, and what of the inertia that may stand in the way of our explicitly expressing and recording our consent? At this point a presumed consent theorist would direct her focus on what it is to consent. For the presumed consent theorist, an absence of explicit consent does not leave the prohibition in place, provided that there are sufficient opportunities for refusal.

- Normative act: $\mathrm{R}$ refrains from signaling her refusal (and, given that there is ample, known opportunity to do so, $\mathrm{R}$ can be presumed to consent).

- Normative end position: It is permissible for $\mathrm{S}$ to do $\mathrm{F}$.

But how does normative consent theory deal with the obstacle posed by a lack of explicit consent? Here there seem to be two routes that the theory follows, both of which are problematic, but for different reasons.

\section{Normative Consent Theory: Conservative Version}

The first route is a conservative one. That is, it accepts the standard normative start position that removing and using organs is prohibited without consent. Some aspects of Saunders's discussion suggest that this is what the normative consent theory is committed to. Consider the following: "Organ donation saves (and improves) lives, which creates a prima facie duty to donate. Most people probably can save lives at little, if any, cost to themselves (I deal with possible excuses, such as conscientious objections, in the following section), placing them under a duty to consent. ${ }^{\prime 18}$ Here it looks like a requirement to gain consent is retained as part of the normative start position; consent is required but people are under a duty to give it. Or, consider the following remark about the role of refusals (which we will return to subsequently in more detail): "The right [people] have to their body like many other rights (e.g., free speech or property) includes the right to do wrong, by refusing to let someone use their organs. Their explicit refusal of consent still has force, as when one partner refuses sexual contact." 19 This, again, makes it look as if consent is in the picture: if it were not, how can one refuse to give it? Similarly, for those who do not refuse, "we are allowed to use their organs, not because they have actually consented or because we presume consent on their part, but simply because they morally ought to consent and that makes their lack of actual consent normatively irrelevant." 20 Once again, this makes it look like consent has a normative role to play; one can 
give it or refuse it, but because one is under a duty to consent, a lack of consent plays the same role as consent normally would.

But does the idea of a duty to consent make sense? Saunders talks of its being "wrong of people to refuse consent to donation." Indeed, more strongly, he claims that "the argument rests on one crucial premise: that it is wrong for (most) people to withhold their consent to post-mortem organ donation." ${ }^{21}$ This idea, that it is wrong to withhold consent, features again in the summary that introduced normative consent theory previously: "If it is wrong of people to refuse consent to donation, then we may be permitted to take their organs, although they have not actually consented (explicitly or implicitly)., ${ }^{\prime 22}$

But suppose we accept this one "crucial premise" that it is wrong of people to refuse to consent. This is not sufficient for the normative consent theory to offer an alternative to current opt-out models. If we hold onto the standard normative start position-it is prohibited to use organs without consent- then the mere fact that it is wrong of a person not to consent does not by itself remove the prohibition. It may be wrong of me not to consent to a poor person's taking possessions of mine that I have little use for, but the wrongness by itself does not render their taking them permissible. Similarly, in the context of organ donation, we might hold that those who do not currently opt in are wrong in their failure to do so, but the mere fact of the wrongness of their action does not make it permissible to use their organs postmortem.

So, it seems that normative consent theory needs something stronger: rather than holding that it is merely wrong not to give consent, perhaps the claim is that people are obliged to give consent. But this stronger assumption is in tension with the normative start position that we are taking for granted:

- Normative start position: It is impermissible for $\mathrm{S}$ to do $\mathrm{F}$ unless $\mathrm{R}$ consents.

- Additional assumption: $\mathrm{R}$ is obliged to consent to S's doing F.

How strong is this obligation? It looks as though the obligation must be quite strong, strong enough to override the prohibition in the normative starting position. But if $\mathrm{R}$ is strongly obliged to consent to S's doing $\mathrm{F}$, then $\mathrm{R}$ has no right not to do so. But this means that the notion of consent (and refusal) is redundant in this context. In what sense can one freely give one's consent to something if one is not permitted not to do so? The starting position is one in which organ use is prohibited without consent, but if all are obliged to consent, there seems to be nothing anyone can do to bring about normative change.

However, it is clear that Saunders does not intend the obligation to be so strong. Saunders argues that although we are obliged to give consent to the use of organs postmortem, in some cases it may be justifiable to refuse to give consent: "Note that I only claim that most people are under an obligation to donate their organs after death. It is permissible for them to withhold their organs only when donation would impose costs upon them that they are not required to bear to save a life." ${ }^{\prime 23}$ Those whose religious convictions prohibit donation might be justified in their refusal. However, Saunders also allows that people should be permitted to opt out, even if postmortem donation would not impose substantial costs or burdens on them.

These people are rather like those who refuse to save a drowning child because they do not want to get their clothes wet. Their action may be morally unjustifiable, but it does not follow that we should refuse to 
respect their wishes. If they explicitly dissent, by opting out of the system, then we do not use their organs. Patients are generally allowed to refuse medical interventions, even for bad reasons. ${ }^{24}$

But this means that the theory entails the following:

- Conclusion: $\mathrm{R}$ is obliged to consent to S's doing F, unless R refuses.

On this conservative interpretation, organ use is prohibited without consent. However, not only is it wrong not to consent, but we are obliged to consent. This undermines the normative relevance of consent: if it is obligatory, we are not free to give our consent. The theory also gives a role to refusals, but this makes it look like we are capable of refusing to permit the use of our organs, but not capable of consenting to their use, even though consent is required for their use.

The tensions here all arise because, according to this conservative interpretation, we are keeping the normative starting position intact. However the conservative interpretation of the theory is not the only one possible.

\section{Normative Consent Theory: Radical Version}

Other remarks made by Saunders suggest a radical departure from the standard normative starting point: "Framing the issue in terms of presumed consent, however, is problematical, because it suggests that actual consent is necessary . . . this is only problematical if we continue to accept the premise that we need someone's actual consent before we can use their organs." ${ }^{25}$ This suggests an alternative normative starting point:

- Normative starting point (radical): It is permissible for $\mathrm{S}$ to do F without R's consent.

This normative starting point allows us to make sense of the role that the normative consent theory gives to refusals but in a way that involves a radical departure from standard opt-out models. In standard models it is consent that has the normative transformative power. Consent renders permissible what would otherwise be prohibited. In this radical version of normative consent theory, however, consent is not necessary; it is refusals (or vetoes) that have normative power. An individual can prohibit what is permissible without her refusal.

The radical version avoids some of the problems of the conservative version. There is no puzzle about how people can be obliged to consent, because on the radical version, their consent is not necessary. In the radical version, consent has no role to play, except, bizarrely, when someone has already exercised their power of refusal. Suppose a person has opted out and thus has activated the prohibition of the use of her organs postmortem. Suppose she then changes her mind. Presumably the prohibition is waivable, so insofar as she is able to revoke her refusal, she can give consent to the use of her organs. But this means that according to normative consent theory unless one has previously refused to permit the use of one's organs, one cannot consent to their use.

The radical version also allows us to make sense of the role of refusals. The problem with the conservative version was that it retained a starting position in 
which consent has an essential normative role to play. But once we take away the assumption that consent is necessary, we can realign things, with refusals being given normative power. The difference is that the default - the starting position-is that the use of organs is permissible, unless people exercise their autonomy in refusing.

In order to make the normative consent theory intelligible and coherent, we have to view it as one that rejects the normative start position in which consent is necessary for permissible use of organs postmortem. In this version of the theory, consent has no role to play, except in the unusual circumstances noted previously. This interpretation is thus more coherent, but it is not a consent theory.

\section{Conclusion}

Normative consent theory is meant to provide an alternative to standard opt-out models of organ donation. The key question is how organ use postmortem can be permissible without explicit consent. Estlund's normative consent theory faces-at an abstract level - a similar conceptual problem: how, in consent theories of political obligation, can such obligations be grounded without explicit consent? But Estlund's normative consent theory is best viewed not as one that identifies a novel way in which consent plays a normative role but as one that denies the necessity of consent to the normative issues at hand: because we are obliged to undertake certain obligations, refusal is not an option, and consent has no role to play. Estlund's normative consent theory is not a consent theory at all.

Saunders seeks to draw on Estlund's theory but is torn in different directions in doing so. In its conservative interpretation, Saunders's theory seeks to hold onto a role for consent. However, the fact that it is wrong not to give consent does not transform the normative landscape. It may already be wrong for us not to consent to permit use of our organs postmortem, but that fact by itself does not render their use permissible. On the other hand, if it is argued that we are obliged to permit the use of our organs, the notion of consent is otiose. If we then introduce the right to refuse, we seem to end up with a strong obligation to consent, unless we don't want to. The conservative interpretation is thus unstable, because it seeks to retain the idea that consent is necessary for permissible use of organs while at the same time introducing an obligation to consent that rules out its operation (and then, to round things off, it seeks to acknowledge the importance of autonomy by giving a role to refusals).

The radical variant is more in keeping with our interpretation of Estlund's theory. That is, rather than involving the claim that consent is somehow obligatory, it simply involves a rejection of the original normative starting position in which consent is necessary. According to the radical version, the use of organs is permissible without consent, but a prohibition can be activated by an act of refusal. It should be clear that it is very misleading to call normative consent theory a consent theory at all, for consent has no role at all to play, save in those cases in which a previous refusal-which activated a prohibition-is revoked.

Saunders does note that the theory may seem to have little to do with consent but responds that the theory is framed in terms of consent because "this is the way the debate has been phrased up to now. More importantly, normative consent retains some connection to the will. ... An opt-out system allows reluctant donors to veto the use of their organs." 26 
But this is disingenuous. Consent, in this model, only comes into play as the revocation of a prior refusal. To call the theory a normative consent model of organ donation is almost an oxymoron, because, given the normative starting position, consent has (almost) no role to play. Perhaps this is one good reason why the theory is framed in terms of consent (even when it renders consent otiose): the label conceals the radical nature of the model.

There is something appealing about the theory, at least considered in abstraction: it performs a neat balancing act, one that gives due weight to the consequentialist case for an obligation to donate while retaining a role for the individual will via the power to refuse. But we should be clear from the start that it is not a consent theory. Normative consent is not consent!

The normative "consent" model does avoid some of the technical problems that plague the presumed consent model (it does not have to secure a plausible conception of presumed consent that has normative force). But there are other reasons why presumed consent theories are taken to be objectionable. For example, one reason why many members of the public (and journalists of a particular bent) are opposed to opt-out systems is that they leave the onus on the individuals to ensure that they have opted out, and they may not know that they can, they may not understand how to, or they may be confused about the whole process. Such people, so the worry goes, risk having their organs removed against their will. The normative (non-consent) theory meets this objection with the following reply: "It is permissible to use your organs unless you activate a prohibition by opting out." It is worth keeping in mind how such a theory would be met if proposed as public policy. Presumed consent theory shares with opt-out theory the assumption that the use of organs postmortem is impermissible without consent. It is not clear to me that a theory that starts with the premise that postmortem use is permissible without consent-unless a refusal is made-would fare any better in a politically unreceptive or opposed media. If people are willing to campaign against presumed consent because it involves the state's "ownership" (or even "nationalization") of their bodies, the model here is unlikely to be any more palatable.

However, the normative consent theory is not meant to be a legal theory, nor is it meant to be an immediate proposal for policy revision. The argument is an ethical one: given that our organs are of no use to us after death, and given that their use can save and greatly improve the lives of others, the normative starting point that involves a prohibition without consent may not be ethically justifiable. There is, to my mind, something important in this line of thought, but it ought not to be cast in terms of providing a consent theory of organ donation.

\section{Notes}

1. HTA 2004, Schedule 1, Part 1, (7).

2. E.g., a BBC survey in 2005 found that 90 percent of people were in favor of organ donation: http://www.bbc.co.uk/pressoffice/pressreleases/stories/2005/08_august/21/donation.shtml (last accessed 24 Aug 2012). The UK Organ Donation Taskforce offers a more cautious figure of "between 65\% and 90\%" (p. 18). UK Department of Health, Organ Donation Task Force. The potential impact of an opt out system for organ donation in the UK; UK Central Office of Information 2008, p. 18; available at http://www.dh.gov.uk/prod_consum_dh/groups/dh_digitalassets/@dh/ @en/documents/digitalasset/dh_090303.pdf (last accessed 24 Aug 2012).

3. The BBC survey notes that $45 \%$ of respondents claimed they had not opted in because "they hadn't really thought about it." This, of course, may be disingenuous, along the lines of "I don't give to charity because I didn't know people were in need." 
4. In the UK, currently 1,000 people a year die while waiting for transplants. See note 2 , UK Dept of Health 2008.

5. The shift from opt-in to opt-out systems may not be as important as other institutional, cultural, and economic factors. E.g., see Rithalia A, McDaid C, Suekarran S. Impact of presumed consent for organ donation on donation rates: A systematic review. British Medical Journal 2009;338:a3162; Abadie A, Gay S. The impact of presumed consent legislation of cadaveric organ donation: A crosscountry study. Journal of Health Economics 2006;25:599-620.

6. E.g., for Erin and Harris, "presumed consent is a fiction. Without the actual consent of the individual, there is no consent." Presumed consent or contracting out. Journal of Medical Ethics 1999;25:365-6, at 365. Erin and Harris offer no argument for this assertion, however.

7. D'Ancona M. Hands off our bodies Mr Brown. The Spectator blog 2008 Jan 13; available at http:// www.spectator.co.uk/coffeehouse/445696/hands-off-our-bodies-mr-brown.thtml (last accessed 24 Aug 2012).

8. Saunders B. Normative consent and opt-out organ donation. Journal of Medical Ethics 2010;36:84-7, at 86 .

9. Estlund D. Democratic Authority: A Philosophical Framework. Princeton, NJ: Princeton University Press; 2007.

10. Note the shift to absence of consent, rather than refusal. This is an important contrast with Estlund's theory, as we shall see subsequently. See note 8, Saunders 2010, at 86.

11. Potts M, Verheijde JL, Rady MY, Evans D. Normative consent and presumed consent for organ donation: A critique. Journal of Medical Ethics 2010;36:498-9.

12. See note 11, Potts et al. 2010, at 499.

13. See note 8 , Saunders 2010 , at 86 .

14. See note 11, Potts et al. 2010, at 499.

15. Since the writing of this article, a reply to these objections has been made by Saunders, which mirrors the responses offered here. Normative consent and organ donation: A vindication. Journal of Medical Ethics 2011;37:362-3.

16. The case arose with regard to the practice of dwarf tossing in Morsang-sur-Orge, in the suburbs of Paris, and ascended through local courts to the French Conseil d'État, leading to a pronouncement by the UN high commissioner on human rights in 2002. See Leget C, Borry P, De Vries R. Nobody tosses a dwarf! The relation between the empirical and normative reconsidered. Bioethics 2009;23:226-35.

17. The distinction between permission and agreement is complex. An act of permission will typically involve undertaking a range of subsidiary obligations (an obligation to refrain from suing, for example). Such fine-tuned distinctions, although important in some contexts, are not of direct importance here.

18. See note 8 , Saunders 2010 , at 86 .

19. See note 8 , Saunders 2010 , at 86 .

20. See note 8 , Saunders 2010, at 86 .

21. See note 8 , Saunders 2010 , at 86 .

22. See note 8 , Saunders 2010 , at 86 .

23. See note 8 , Saunders 2010 , at 86 .

24. See note 8 , Saunders 2010 , at 86 .

25 . See note 8 , Saunders 2010, at 85 .

26. See note 8 , Saunders 2010 , at 86 . 